\title{
What to measure in the level of mathematical thinking among pre-university Science students?
}

\begin{abstract}
Mathematical thinking involves mental operations that are facilitated by the learners' mathematics knowledge and their positive disposition towards mathematical problem solving. It improves problem solving process by adapting various heuristic strategies as well as monitoring and controlling their outcomes in meta-cognitive manner. Thus, it is vital to identify the mathematical thinking level of pre-university science graduates so that ultimately they are well-equipped with the authentic problem solving and thinking skills for their future academic development specifically and nation building generally. This paper presents a theoretical mathematical thinking assessment framework that integrates the measuring dimensions of mathematical thinking with its processes to achieve different mathematical thinking levels among pre-university Science students. The framework provides an overview on what and how to facilitate the development of the students' mathematical thinking level and problem-solving skills. It could be utilized to measure the preparedness of pre-university Science students for their tertiary mathematics education. Retrospectively, the framework could be leveraged to determine whether the aim of mathematics curriculum for secondary school in developing the students' mathematical thinking has been met. On top of it, the framework assists in identifying a pool of potential post-secondary students to embark on tertiary Science, Technology, Engineering and Mathematics education.
\end{abstract}

Keyword: Mathematical education; Mathematical thinking assessment framework; Mathematical thinking level; Mathematical thinking process; Pre-university students 